\title{
Risk of natalizumab-associated PML in patients with MS is reduced with extended interval dosing
}

Lana Zhovtis Ryerson, MD, * John Foley, MD,* Ih Chang, PhD, llya Kister, MD, Gary Cutter, PhD, Ryan R. Metzger, PhD, Judith D. Goldberg, ScD, Xiaochun Li, PhD, Evan Riddle, PhD, Karen Smirnakis, MPH, Rachna Kasliwal, MPH, Zheng Ren, PhD, Christophe Hotermans, MD, PhD, Pei-Ran Ho, MD, and Nolan Campbell, PhD

Neurology ${ }^{\circledR}$ 2019;93:e1452-e1462. doi:10.1212/WNL.0000000000008243

\section{Abstract \\ Objective}

To use the large dataset from the Tysabri Outreach: Unified Commitment to Health (TOUCH) program to compare progressive multifocal leukoencephalopathy (PML) risk with natalizumab extended interval dosing (EID) vs standard interval dosing (SID) in patients with multiple sclerosis (MS).

\section{Methods}

This retrospective cohort study included anti-JC virus antibody-positive patients $(\mathrm{n}=35,521)$ in the TOUCH database as of June 1,2017. The effect of EID on PML risk was evaluated with 3 planned analyses using Kaplan-Meier methods stratified by prior immunosuppressant use. Risk of PML was analyzed by Cox regression adjusted for age, sex, prior immunosuppressants, time since natalizumab initiation, and cumulative number of infusions.

\section{Results}

This study included 35,521 patients (primary analysis: 1,988 EID, 13,132 SID; secondary analysis: 3,331 EID, 15,424 SID; tertiary analysis: 815 EID, 23,168 SID). Mean average dosing intervals were 35.0 to 43.0 and 29.8 to 30.5 days for the EID and SID cohorts, respectively. Hazard ratios (95\% confidence intervals) of PML risk for EID vs SID were 0.06 (0.01-0.22, $p<$ $0.001)$ and $0.12(0.05-0.29, p<0.001)$ for the primary and secondary analyses, respectively. Relative risk reductions were $94 \%$ and $88 \%$ in favor of EID for the primary and secondary analyses, respectively. The tertiary analysis included no cases of PML with EID.

\section{Conclusion}

Natalizumab EID is associated with clinically and statistically significantly lower PML risk than SID.

\section{Classification of evidence}

This study provides Class III evidence that for patients with MS, natalizumab EID is associated with a lower PML risk than SID.

\author{
Correspondence \\ Dr. Campbell \\ nolan.campbell@biogen.com
}

\section{RELATED ARTICLE}

\section{Editorial}

Dosing interval of natalizumab in MS: Do good things come to those who wait?

Page 655

\section{MORE ONLINE}

\section{$\rightarrow$ Class of Evidence}

Criteria for rating

therapeutic and diagnostic studies

NPub.org/coe

\footnotetext{
*These authors contributed equally to this work.

From the Department of Neurology (L.Z.R., I.K.), NYU Langone Health, New York University, New York; Rocky Mountain MS Clinic (J.F., R.R.M.), Salt Lake City, UT; Biogen (I.C., E.R., K.S., R.K., Z.R., C.H., P-R.H., N.C.), Cambridge, MA; University of Alabama School of Public Health (G.C.), Birmingham; and Division of Biostatistics (.D.G., X.L.), New York University School of Medicine, New York.

Go to Neurology.org/N for full disclosures. Funding information and disclosures deemed relevant by the authors, if any, are provided at the end of the article. 


\section{Glossary}

$\mathrm{ADI}=$ average dosing interval; $\mathbf{C I}=$ confidence interval; $\mathbf{E I D}=$ extended interval dosing; $\mathrm{HR}=$ hazard ratio; $\mathrm{JCV}=\mathrm{JC}$ virus; MS = multiple sclerosis; PML = progressive multifocal leukoencephalopathy; SID = standard interval dosing; TOUCH = Tysabri Outreach: Unified Commitment to Health.

Natalizumab, a monoclonal antibody directed against the a4-integrin cell adhesion molecule, is an efficacious treatment for relapsing forms of multiple sclerosis (MS), as demonstrated by randomized clinical trials ${ }^{1,2}$ and real-world data. ${ }^{3,4}$ The recommended treatment schedule $(300 \mathrm{mg}$ IV infusion every 4 weeks) was selected to provide $>80 \%$ saturation of mononuclear cell $\alpha 4 \beta 1$-integrin receptors for $\approx 1$ month after administration., 5 For patients previously exposed to JC virus (JCV), natalizumab treatment is associated with a risk of progressive multifocal leukoencephalopathy (PML). ${ }^{7}$ Established risk factors for PML in anti-JCV antibody-positive patients include the level of anti$\mathrm{JCV}$ antibodies in serum as assessed by anti-JCV antibody index, the use of immunosuppressant therapy before natalizumab initiation, and the duration of natalizumab treatment. ${ }^{8,9}$

In real-world practice, treatment cessation, treatment interruptions, and deviations from recommended treatment schedules are not unusual. Several retrospective studies have investigated the effect of extended interval dosing (EID) schedules (infusion intervals $>4$ weeks) with the goal of maintaining natalizumab efficacy while reducing the risk of PML. ${ }^{10,11}$ These studies, which are limited by nonrandomized designs, small patient populations, and variable definitions of EID, nevertheless suggest that patients switching to natalizumab EID after a period of standard interval dosing (SID) continue to do well. However, because PML is a rare event, these studies did not have sufficient statistical power to assess whether EID is associated with risk reduction of PML relative to SID. Therefore, the safety of natalizumab EID with respect to PML risk is not fully known.

The Tysabri Outreach: Unified Commitment to Health $\left(\mathrm{TOUCH}^{\circledR}\right)$ program, a risk evaluation and mitigation strategy mandated by the US Food and Drug Administration, ${ }^{7,12}$ is designed to inform health care providers and patients about PML and its known risk factors; to warn against concurrent use of antineoplastic, immunosuppressant, or immunomodulatory agents; and to monitor patients for the development of PML and other serious opportunistic infections during treatment. The TOUCH database captures all natalizumab infusion records, patient demographic information, prior immunosuppressant therapy, and anti-JCV antibody status data (since February 2012). It is the largest dataset in the world that can provide safety information associated with alternative dosing intervals of natalizumab.

\section{Methods}

\section{Study design}

This retrospective cohort study included data collected in the TOUCH program as of June 1,2017, and included all patients with a known positive anti-JCV antibody serostatus and a known status of prior immunosuppressant use. PML data up to June 1, 2017, from Biogen's Tysabri Global Safety Database were also included in the study. Patients with a history of any interval $>12$ weeks (dosing gap) or $<3$ weeks (overdose) between 2 consecutive infusions were excluded. The 3 planned analyses and their respective EID and SID inclusion criteria were developed and finalized under conditions blinded to PML events.

\section{Primary research question}

The objective of this study was to use the large, real-world TOUCH dataset to determine whether natalizumab EID was associated with a reduced PML risk compared with SID. Because there is no precise understanding of the mechanism whereby natalizumab causes PML or how dosing schedules might affect PML risk, 3 planned analyses, each with different EID inclusion criteria, were used to evaluate both the effect of EID on PML risk and its potential mechanism.

\section{Classification of evidence}

This study provides Class III evidence that in patients with relapsing-remitting MS, natalizumab EID is associated with statistically and clinically significant reductions in PML risk compared with SID. The evidence from this study is rated Class III for the following reasons: retrospective cohort study design, imbalances between EID and SID groups at baseline, and limited available data on potential confounders.

\section{Data collection}

Patient data collected in TOUCH include demographic information, the date and dose of each natalizumab infusion, the date and results of anti-JCV antibody testing (since 2012) performed in the previous 12 months, and treatment with immunomodulatory/immunosuppressant therapies in the previous 6 months. The records of cases of PML are captured and maintained in a separate pharmacovigilance database (Tysabri Global Safety Database).

\section{Planned analyses and inclusion criteria}

The TOUCH dataset demonstrates considerable variability in natalizumab dosing, whether intentional or unintentional, in US clinical practice. Furthermore, optimal EID infusion intervals and treatment duration are unknown. Therefore, 3 distinct 
analyses of EID vs SID were planned for this study. Each analysis used different inclusion criteria (definitions) for patients on EID and SID based on the number of doses received during specified time periods to test different hypotheses about the potential effect of EID on PML risk (figure 1). Patients could meet inclusion criteria for $>1$ analysis.

The primary analysis assessed PML risk associated with the last 18 months of recorded infusion history. Patients who had received $\leq 15$ infusions in the last 18 months of treatment were included in the primary EID (EID- $1^{\circ}$ ) analysis group; patients who had received $>15$ infusions in the last 18 months of treatment were included in the primary SID (SID- $1^{\circ}$ ) analysis group.

The secondary analysis assessed the effect of any prolonged period of EID in the patient's infusion history on PML risk. For this analysis, individual infusions were categorized as EID or SID. An EID infusion was defined as any infusion preceded by $\leq 10$ infusions in the prior 365 days. Patients receiving such EID infusions consecutively for $\geq 6$ months were included in the secondary EID (EID-2 ${ }^{\circ}$ ) analysis group. Similarly, an SID infusion was defined as any infusion preceded by $>10$ infusions in the prior 365 days, and patients receiving such infusions consecutively for $\geq 6$ months were included in the secondary SID (SID-2 ${ }^{\circ}$ ) analysis group. Patients with a history of both $\geq 6$ months of EID- $2^{\circ}$ dosing and $\geq 6$ months of SID- $2^{\circ}$ dosing were included in the EID- $2^{\circ}$ cohort only. Patients with $>1$ EID- $2^{\circ}$ regimen were excluded, increasing the analytical rigor.

The tertiary analysis assessed the effect of a dosing history consisting primarily of EID on PML risk. Patients who had received $\leq 10$ infusions per year (annualized number of infusions) over their entire treatment history were included in the tertiary EID (EID- $3^{\circ}$ ) analysis group; patients who had received $>10$ infusions per year were included in the tertiary SID (SID-3 $3^{\circ}$ analysis group.

Two prespecified sensitivity analyses were performed. In the first, cases of PML occurring before 2012 (before collection of anti-JCV antibody test results in TOUCH) were assumed to be anti-JCV antibody positive and added to the 3 planned analyses described above. In the second sensitivity analysis, alternative EID definitions of $\leq 13$ infusions in the last 18 months and $\leq 9$ infusions over any 12 -month period were used for inclusion in the primary and secondary EID analysis

Figure 1 Descriptions of the 3 planned analyses of PML risk and the definitions of EID and SID used in this study

\begin{tabular}{ll}
\hline EID infusion & Unclassified infusion \\
SID infusion & Final dose
\end{tabular}

Primary analysis: Tests effect of last 18 months of dosing history on PML risk

Definition

- EID-1 $1^{\circ}: \leq 15$ infusions in the last 18 months (548 days)

- SID-1 ${ }^{\circ}$ : >15 infusions in the last 18 months (548 days)

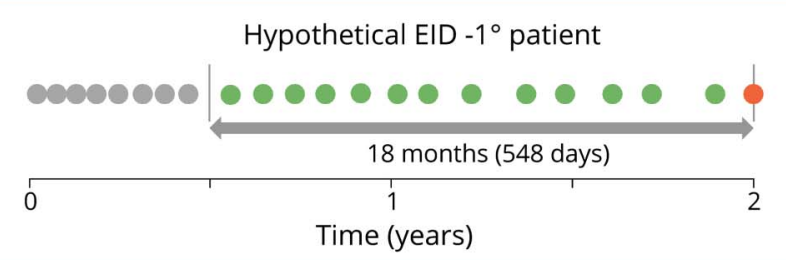

\section{Secondary analysis: Tests effect of any prolonged period of EID on PML risk}

Definition

- EID-2 $2^{\circ}$ : Any infusion preceded by $\leq 10$ doses in the prior 365 days; patients received consecutive EID- $2^{\circ}$ infusions for $\geq 6$ months

- SID-2 $2^{\circ}:>10$ doses over 365 days prior to any infusion;

patients received consecutive $\mathrm{SID}-2^{\circ}$ infusions for $\geq 6$ months
Hypothetical EID-2 ${ }^{\circ}$ patient

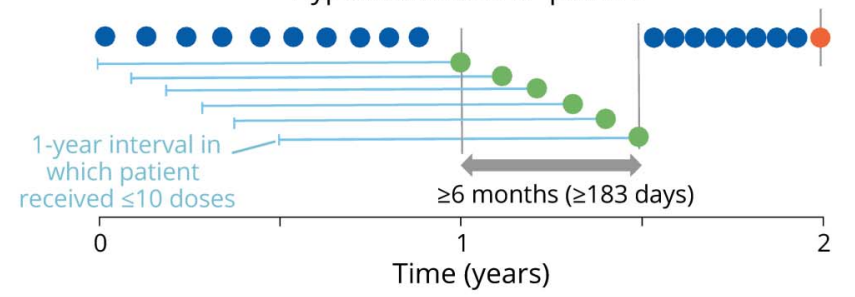

Tertiary analysis: Tests effect of a dosing history consisting primarily of EID on PML risk

\section{Definition}

- EID-3 $: \leq 10$ infusions/year over entire treatment duration

$\cdot$ SID-3 : $>10$ infusions/year over entire treatment duration
Hypothetical EID-3ำ patient

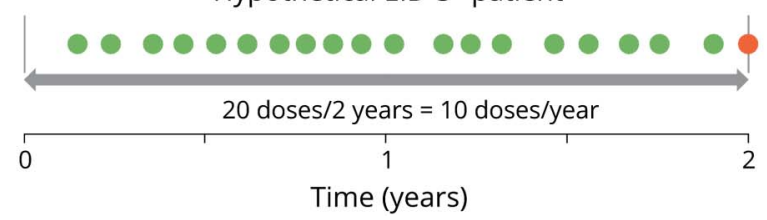

Each hypothetical patient dosing diagram depicts 2 years of infusion history. EID = extended interval dosing; PML = progressive multifocal leukoencephalopathy; SID = standard interval dosing. 
groups, respectively. Alternative inclusion criteria for the tertiary analysis were not tested.

All analyses were performed on deidentified data collected in the TOUCH program with patient consent and on PML data collected via standard pharmacovigilance practices to monitor natalizumab safety as required by regulatory authorities. Additional informed consent was not required.

\section{Statistical analysis}

Demographic and treatment history data for the overall study population and for each EID analysis cohort were summarized by descriptive statistics. For the 3 planned analyses, time-toevent (PML occurrence) analyses using Kaplan-Meier estimates of cumulative risk were performed for the EID and SID cohorts. Time to event was based on time since initiation of natalizumab treatment. A log-rank test was performed to compare the time to event between the EID and SID cohorts. The conditional probability of PML in each exposure epoch (defined as a series of 12 infusions) was derived for the EID and SID cohorts with the life-table method stratified by prior immunosuppressant use. The PML hazard ratio (HR) in the EID and SID cohorts was estimated with a time-varying covariate Cox regression model adjusted for age, sex, calendar year of the start of natalizumab treatment, and prior immunosuppressant use (yes/no) as covariates and the cumulative number of infusions as the time-varying covariate.

For each analysis, the PML HR estimate (EID vs SID) and its 95\% confidence interval (CI) from the Cox model were the primary basis of inference. Specifically, if the HR upper 95\% CI limit was $<1$, the EID cohort would be considered to have a lower risk of PML than the SID cohort. If the HR point estimate was $\geq 0.9$ and $\leq 1.1$, the EID and SID cohorts would be considered to have similar risks. If the HR lower 95\% CI limit was $>1$, the EID cohort would be considered to have greater risk. At the time of analysis plan specification, the anticipated study population sizes and expected number of PML events predicted $\approx 85 \%$ power to detect a risk reduction $\geq 50 \%$ (i.e., an $\mathrm{HR} \leq 0.5$ ) as defined by the above rules of inference.

The statistical analysis plan was developed and finalized under conditions blinded to PML events. PML data from the Tysabri Global Safety Database were merged with TOUCH after the analysis plan was finalized.

\section{Data availability}

Data from the TOUCH program and pharmacovigilance databases used in the analyses described in this article are the sole property of Biogen and are not publicly available. The authors and Biogen are fully supportive of allowing independent assessment and verification of these results. Biogen has established processes to share protocols, clinical study reports, study-level data, and patient-level data with qualified scientific researchers (supplementary file 1, links. lww.com/WNL/A974).

\section{Results}

\section{Patients}

Of the 90,038 patients enrolled in TOUCH as of June 1, 2017, 35,521 were anti-JCV antibody positive and eligible for this study (figure 2). After application of the prespecified EID and SID inclusion criteria, the study populations included 1,988 patients on EID and 13,132 on SID in the primary analysis, 3,331 patients on EID and 15,424 on SID in the secondary analysis, and 815 patients on EID and 23,168 on SID in the tertiary analysis. The most common reasons for patient exclusion were the presence of dosing gaps or overdoses in treatment history (primary, secondary, and tertiary analyses) and $<18$ months of available dosing data (primary analysis only).

The baseline demographics in the EID and SID groups were well balanced across the 3 analyses (table 1). In all 3 analyses, patients on EID had more natalizumab infusions and longer total duration of natalizumab treatment than patients on SID. Patients on EID included in the primary analysis had received a median (range) of 37 (1-117) infusions before starting EID. In the secondary analysis (in which each infusion was defined as either EID or SID), patients in the EID- $2^{\circ}$ group had received a median (range) of 25 (1-121) infusions before starting EID. For all 3 analyses, the median average dosing interval (ADI) over the entire treatment duration was 33.5 to 41.4 days for patients on EID and 29.4 to 29.8 days for patients on SID. In the primary analysis during the cohort-defining final 18 months of treatment, median ADI (interquartile range) was $42.2(39.0-49.1)$ for patients on EID patients and 29.7 (28.6-31.4) for those on SID.

\section{Risk assessment}

The Kaplan-Meier-estimated cumulative risk of PML was significantly lower with EID than with SID (figure 3, A-C). In the primary and secondary analyses, cumulative risk appeared to separate after 24 to 36 months, with separation increasing at later time points. Cox regression analysis also identified significant reductions in PML risk with EID treatment in the primary and secondary analyses (both $p<0.001$; table 2). The covariate-adjusted HR in the primary analysis was 0.06 (95\% CI $0.01-0.22$ ), corresponding to a relative risk reduction of $94 \%$ in patients in the EID- $1^{\circ}$ group vs those in the SID- $1^{\circ}$ group. In the secondary analysis, the covariate-adjusted HR was 0.12 (95\% CI 0.05-0.29), corresponding to a relative risk reduction of $88 \%$ in patients in the EID- $2^{\circ}$ group vs patients in the SID- $2^{\circ}$ group. Because no cases of PML were observed with EID in the tertiary analysis, the risk-reduction point estimate was $100 \%$, and the Cox regression model 95\% CI was nonestimable.

Prior immunosuppressant use significantly increased PML risk. Covariate-adjusted HRs were 2.92 (95\% CI 1.67-5.11, $p<0.001)$ in the primary analysis and 2.90 (95\% CI 1.60-5.27, $p=0.001$ ) in the secondary analysis (table 2). However, the significance of this observation is limited by the small number of 


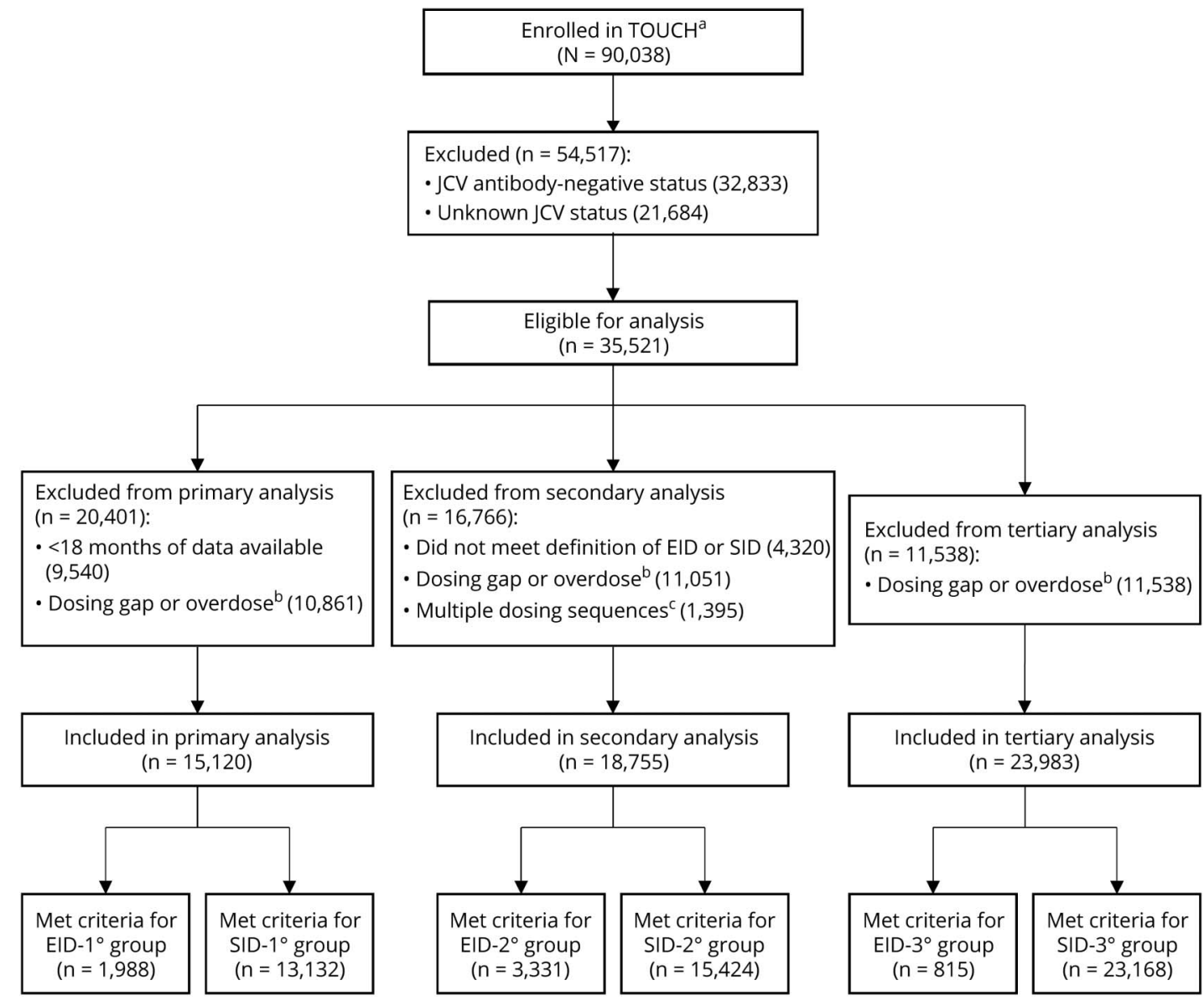

For inclusion in any analysis, patients must have had no dosing gaps (defined as an interval $>12$ weeks between 2 consecutive infusions) or overdoses (defined as an interval <3 weeks between 2 consecutive infusions). EID = extended interval dosing; JCV = JC virus; PML = progressive multifocal leukoencephalopathy; $\mathrm{SID}=$ standard interval dosing; TOUCH = Tysabri Outreach: Unified Commitment to Health. ${ }^{\mathrm{a} E n r o l l e d ~ n u m b e r ~ a s ~ o f ~ J u n e ~ 1, ~ 2017 . ~}{ }^{\mathrm{b}} \mathrm{At}$ least 1 occurrence of

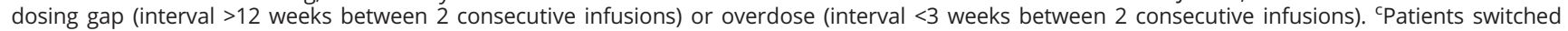
between SID and EID more than once.

patients with immunosuppressant use (95 for EID- $1^{\circ}$ and 175 for $\mathrm{EID}-2^{\circ}$ ).

\section{Sensitivity and post hoc analyses}

The robustness of the 3 analyses was evaluated to determine the effect of study design decisions on the results. The first sensitivity analysis examined the effect of excluding patients without known anti-JCV antibody status by including cases of PML that occurred before 2012 under the assumption that all were anti-JCV antibody positive. This added 1 case of EID and 67 cases of SID PML to the primary analysis, 5 cases of EID and 65 cases of SID PML to the secondary analysis, and 0 cases of EID and 71 cases of SID PML to the tertiary analysis. When the same post-2012 population denominators as the planned analyses were used (because anti-JCV antibody status is mostly unknown for the pre-2012 population), HRs for EID vs SID ranged from $<0.01$ to 0.09 in all 3 analyses (table 3 ).

The second sensitivity analysis investigated the effect of the number of EID doses required for inclusion in EID groups by using alternative eligibility criteria. The risk of PML was significantly lower for EID than for SID with the use of the alternative EID inclusion criteria of $\leq 13$ infusions in the previous 18 months (HR 0.10, 95\% CI 0.02-0.45) in the primary analysis or $\leq 9$ infusions over 12 months (HR 0.01 , 95\% CI < 0.01-0.09) in the secondary analysis (table 3). Alternative EID inclusion criteria in the tertiary analysis were not explored because no cases of EID- $3^{\circ}$ PML were observed.

Two post hoc analyses were carried out to address the influence of potential selection biases on the composition of the EID analysis cohorts. When the effect of excluding patients with dosing gaps (intervals $>12$ weeks between 2 infusions) was assessed by including patients with dosing gaps in the 3 planned analyses of PML risk, the resulting HRs ranged from 0.08 to 0.16 (table 3 ).

Although all patients included in this study had tested positive for anti-JCV antibodies at least once, a second post hoc analysis was conducted to evaluate whether the duration of 
Table 1 Baseline characteristics, natalizumab exposure, and ADIs

\begin{tabular}{|c|c|c|c|c|c|c|}
\hline \multirow[b]{2}{*}{ Characteristic } & \multicolumn{2}{|l|}{ Primary analysis } & \multicolumn{2}{|c|}{ Secondary analysis } & \multicolumn{2}{|l|}{ Tertiary analysis } \\
\hline & $\begin{array}{l}\text { EID-1 } 1^{\circ} \text { group } \\
(n=1,988)\end{array}$ & $\begin{array}{l}\text { SID-1 } 1^{\circ} \text { group } \\
(n=13,132)\end{array}$ & $\begin{array}{l}\text { EID- } 2^{\circ} \text { group } \\
(n=3,331)\end{array}$ & $\begin{array}{l}\text { SID- } 2^{\circ} \text { group } \\
(n=15,424)\end{array}$ & $\begin{array}{l}\text { EID-3 group } \\
(n=815)\end{array}$ & $\begin{array}{l}\text { SID-3 } 3^{\circ} \text { group } \\
(n=23,168)\end{array}$ \\
\hline Women, $\mathrm{n}(\%)^{\mathrm{a}}$ & $1,376(69)$ & $8,846(67)$ & $2,293(69)$ & $10,239(66)$ & $539(66)$ & $15,636(67)$ \\
\hline Age at first infusion, mean (SD), y & $42.9(11.3)$ & $44.0(11.0)$ & $43.0(11.2)$ & $43.9(11.4)$ & $42.0(11.4)$ & $43.9(11.6)$ \\
\hline $\begin{array}{l}\text { Prior immunosuppressant } \\
\text { therapy, } n(\%)^{b}\end{array}$ & $95(5)$ & $689(5)$ & $175(5)$ & $799(5)$ & $49(6)$ & $1,310(6)$ \\
\hline $\begin{array}{l}\text { No. of natalizumab infusions, } \\
\text { median (minimum, maximum) }\end{array}$ & $50(11,132)$ & $46(17,142)$ & $51(6,137)$ & $27(7,142)$ & $32(2,103)$ & $26(1,142)$ \\
\hline $\begin{array}{l}\text { Duration of natalizumab } \\
\text { treatment, median (minimum, } \\
\text { maximum), mo }\end{array}$ & $59(19,130)$ & $44(19,131)$ & $56(8,131)$ & $26(7,130)$ & $43(3,129)$ & $25(1,131)$ \\
\hline \multicolumn{7}{|l|}{$A D I, d$} \\
\hline Mean (SD) & $36.7(4.9)$ & $30.0(1.6)$ & $35.0(4.9)$ & $29.8(1.7)$ & $43.0(5.4)$ & $30.5(2.6)$ \\
\hline Median (Q1, Q3) & $35.5(33.3,38.8)$ & $29.7(28.8,30.8)$ & $33.5(31.7,36.9)$ & $29.4(28.7,30.5)$ & $41.4(39.2,44.8)$ & $29.8(28.8,31.4)$ \\
\hline \multicolumn{7}{|c|}{$\begin{array}{l}\text { Abbreviations: } \mathrm{ADI}=\text { average dosing interval (over entire treatment history); EID = extended interval dosing; Q1 = first quartile; Q3 = third quartile; SID = } \\
\text { standard interval dosing. } \\
\text { Figure } 1 \text { provides definitions of EID and SID in the primary, secondary, and tertiary analyses. } \\
\text { a Information on patient sex was missing for <1\% of patients in each group. } \\
\text { b Information on prior immunosuppressant therapy was missing for } 4 \% \text { to } 5 \% \text { of patients in each group. }\end{array}$} \\
\hline
\end{tabular}

anti-JCV antibody seropositivity affected risk estimates. Longitudinal anti-JCV antibody status (i.e., antibody status conversion from negative to positive at some point in time) as a time-varying covariate was incorporated into the Cox regression model. The resulting HR (95\% CI) estimates were $0.05(0.11-0.18)$ in the primary analysis and $0.11(0.04-0.26)$ in the secondary analysis (table 3 ). This sensitivity analysis was not performed for the tertiary analysis.

EID was associated with a reduction in the conditional risk of PML in each successive epoch of natalizumab treatment for all 3 definitions of EID and SID (table 4). Over the first 4 treatment epochs ( $\leq 48$ infusions), only 1 case of PML (in the secondary analysis) was observed in EID groups; no cases were observed in the primary and tertiary analyses. In the fifth and sixth epochs (49-72 infusions), PML risk was substantially lower for EID than for SID across all 3 analyses (table 4).

\section{Cases of EID PML}

Thirteen cases of PML were identified among patients meeting primary and secondary EID inclusion criteria. One case met the primary analysis criteria only; 10 cases met the secondary analysis criteria only; and 2 cases met criteria for both analyses. There were no cases of PML in the tertiary analysis. At the time of PML diagnosis, 8 of 13 patients, all of whom were included in the secondary analysis, had switched back to SID from EID and had been on SID for $\geq 28$ weeks immediately before PML diagnosis (data not shown). On the basis of 3 different measures, patients with PML with a history of EID had greater natalizumab exposure than their respective overall EID cohorts. The patients with EID PML had longer (median [quartile 1, 3]) natalizumab treatment durations (primary analysis: $74[58,75]$ vs $59[37,87]$ months; secondary analysis: $75[60,85]$ vs $56[36,81]$ months), more (median [quartile 1,3]) natalizumab infusions before starting an EID regimen (primary analysis: $54[37,55]$ vs $37[18,63]$ infusions; secondary analysis: $40.5[19,56.5]$ vs $25[13,44]$ infusions), and more (median [quartile 1, 3]) total natalizumab infusions on average (primary analysis: $68[50,68]$ vs 50 $[31,75.5]$; secondary analysis: $68[58,83]$ vs $51[31,75]$ infusions). Prior immunosuppressant use was also more common in cases of EID PML than in the overall EID cohorts (primary analysis: $33 \%$ vs $5 \%$; secondary analysis: $17 \%$ vs $5 \%$ ). Of the 7 cases of PML for whom pre-PML anti-JCV antibody index values were available, 6 had index values $>1.5$ (data not shown).

\section{Discussion}

To address the question of PML risk with EID, we conducted a retrospective cohort study using patient data collected by the TOUCH program. This is the largest study of PML risk associated with natalizumab EID to date and provides an example of how real-world data derived from a Risk Evaluation and Mitigation Strategy program can be rigorously analyzed to address a clinically meaningful question of risk reduction. Even though PML is an uncommon event, the size of the TOUCH dataset provided sufficient power to produce robust and statistically significant results. We evaluated PML risk in anti-JCV antibody-positive patients who met any of the 3 inclusion criteria for natalizumab EID vs the risk in patients on SID using 3 different prespecified analyses to investigate 
Figure 3 Kaplan-Meier estimates of the cumulative probability of PML in EID vs SID groups in the (A) primary, (B) secondary, and (C) tertiary analyses

A

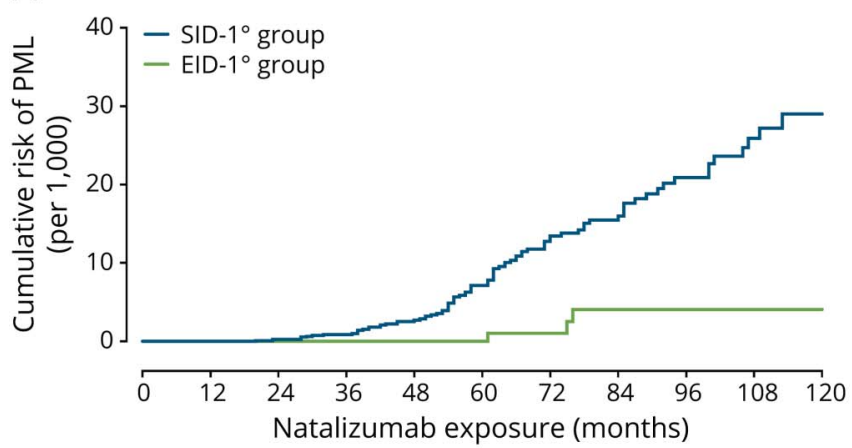

Number of patients at risk ${ }^{\text {b: }}$

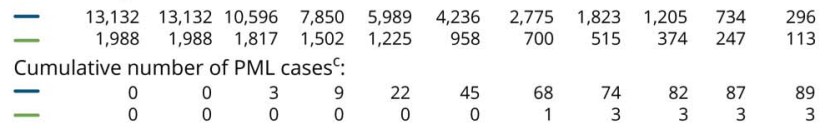

B

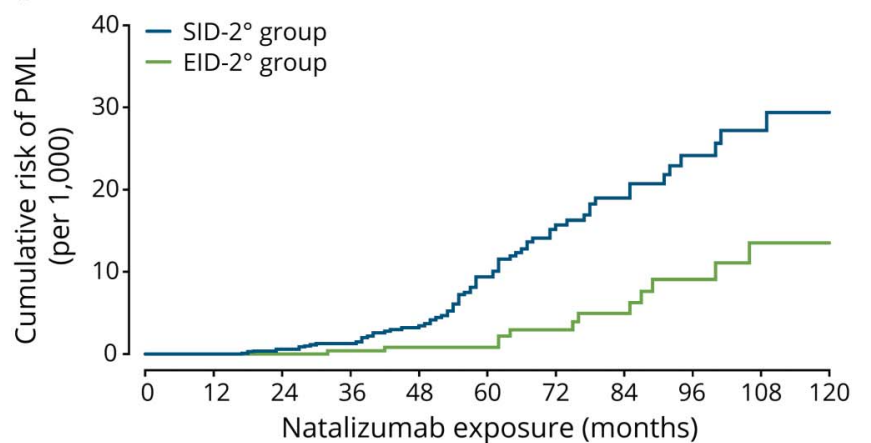

Number of patients at risk:

\begin{tabular}{|c|c|c|c|c|c|c|c|c|c|c|c|}
\hline- & 15,424 & 13,104 & 8,083 & 5,629 & 4,134 & 2,829 & 1,756 & 1,117 & 718 & 440 & 172 \\
\hline & 3,331 & 3,285 & 2,949 & 2,463 & 1,990 & 1,494 & 1,063 & 756 & 535 & 342 & 145 \\
\hline \multicolumn{12}{|c|}{ Cumulative number of PML cases $^{\mathrm{c}}$ : } \\
\hline & 0 & 0 & 6 & 11 & 22 & 43 & 58 & 63 & 68 & 70 & 71 \\
\hline & 0 & 0 & 0 & 1 & & & 5 & & 10 & 12 & 12 \\
\hline
\end{tabular}

C

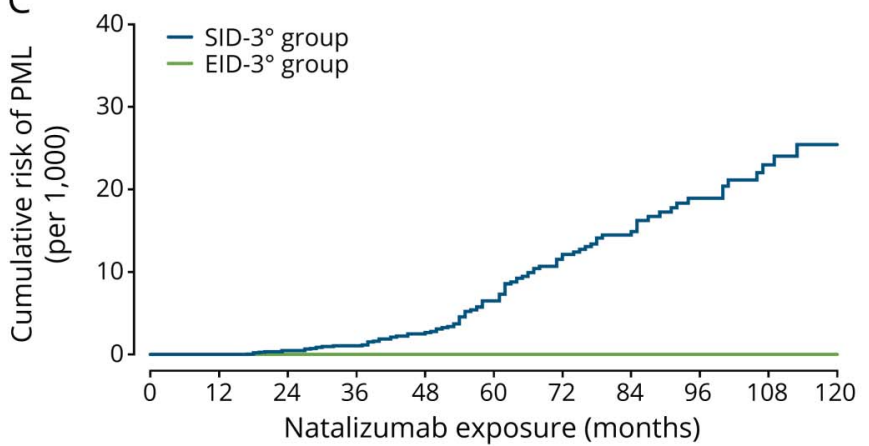

Number of patients at risk ${ }^{\text {b }}$ :

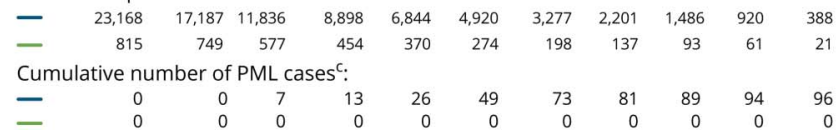

HR (95\% CI) from Cox regression

analysis: $0.06(0.01-0.22) ; p<0.0001$

$94 \%$ reduction in PML risk (EID vs SID)

$p$ value from log-rank test: $<0.0001$
HR $(95 \% \mathrm{Cl})$ from Cox regression

analysis: 0.12 (0.05-0.29); $p<0.0001$

$88 \%$ reduction in PML risk (EID vs SID)

$p$ value from log-rank test: $<0.0001$

$\mathrm{Cl}=$ confidence interval; EID = extended interval dosing; $\mathrm{HR}=$ hazard ratio; $\mathrm{PML}=$ progressive multifocal leukoencephalopathy; SID = standard interval dosing aEID vs SID. Model includes age, sex, prior use of immunosuppressants, EID/SID group, and calendar year at the start of natalizumab treatment as covariates. The Cox regression analysis could not be performed for the tertiary analysis because no cases of PML occurred in the EID- $3^{\circ}$ group. ${ }^{b} \mathrm{Number}$ of patients who were still in the study and did not have PML at the end of the specified time. ${ }^{\circ}$ Cumulative number of cases of PML at the end of the specified time. 
Table 2 Effect of EID vs SID on PML risk in a Cox regression model in the primary and secondary analyses ${ }^{\text {a }}$

\begin{tabular}{|c|c|c|c|c|}
\hline \multirow[b]{2}{*}{ Risk factor } & \multicolumn{2}{|l|}{ Primary analysis } & \multicolumn{2}{|c|}{ Secondary analysis } \\
\hline & $\mathrm{HR}(95 \% \mathrm{Cl})$ & $p$ Value & HR $(95 \% \mathrm{Cl})$ & $p$ Value \\
\hline Age & $1.00(0.98-1.02)$ & 0.999 & $0.99(0.97-1.01)$ & 0.411 \\
\hline Sex (male, female) & $1.05(0.58-1.63)$ & 0.828 & $0.99(0.63-1.57)$ & 0.969 \\
\hline Prior immunosuppressant use (yes, no) & $2.92(1.67-5.11)$ & $<0.001$ & $2.90(1.60-5.27)$ & $<0.001$ \\
\hline Calendar year at the start of treatment & $0.99(0.88-1.12)$ & 0.881 & $0.94(0.83-1.06)$ & 0.327 \\
\hline No. of cumulative infusions & $0.91(0.87-0.95)$ & $<0.001$ & $0.91(0.87-0.94)$ & $<0.001$ \\
\hline Dosing group (EID, SID) & $0.06(0.01-0.22)$ & $<0.001$ & $0.12(0.05-0.29)$ & $<0.001$ \\
\hline
\end{tabular}

Abbreviations: $\mathrm{Cl}$ = confidence interval; EID = extended interval dosing; $\mathrm{HR}=$ hazard ratio; PML = progressive multifocal leukoencephalopathy; SID = standard interval dosing.

Refer to figure 1 for definitions of EID and SID in the primary, secondary, and tertiary analyses.

a Model includes age, sex, prior use of immunosuppressants, EID/SID group, and calendar year at the start of natalizumab treatment as covariates. Modeling could not be performed in the tertiary analysis because no PML events occurred in the tertiary analysis EID group.

a wide range of dosing patterns used in real-world clinical practice. For each of the 3 different analyses, there was a substantial reduction in PML risk with natalizumab EID compared with SID.

The difference in dosing intervals between the overall EID and SID groups was relatively modest (ADI 35-43 days for EID vs 30-31 days for SID). While these values combine different treatment practices and dosing patterns, the results suggest that extending dosing intervals by as little as 1 to 2 weeks may produce a large reduction in PML risk. It is unlikely that the main conclusions of this study were affected by outliers at either end of the ADI range, because patients with any dosing interval $<3$ weeks or $>12$ weeks in their history were excluded from the planned analyses and third-quartile (75th percentile) ADI ranges for the EID cohort were 37 to 45 days.

Prespecified sensitivity analyses were performed to evaluate whether and how the results were affected by the following 2 study design elements: (1) the inclusion only of patients with known positive anti-JCV antibody status and (2) the number of EID infusions required for inclusion in the EID- $1^{\circ}$ or EID$2^{\circ}$ groups. In addition, a post hoc sensitivity analysis was performed to evaluate the effect of excluding patients with a history of dosing gaps ( $>12$ weeks between doses). The results of both the sensitivity and post hoc analyses were comparable to those of the 3 planned analyses, demonstrating the robustness of the risk estimates and further strengthening the main conclusion that natalizumab EID is associated with lower PML risk than SID in at-risk patients.

The possibility that physicians are more likely to switch patients with longer durations of JCV seropositivity to EID created a potential selection bias in the composition of the EID cohorts. When anti-JCV antibody positivity status was accounted for as a time-varying covariate in a second post hoc analysis, the resulting HRs and 95\% CIs were similar to those produced in the original prespecified analyses, indicating that this potential bias did not have a major bearing on the main study conclusions.

The identification of 13 cases of PML among the combined 5,249 patients in the EID- $1^{\circ}$ and/or EID- $2^{\circ}$ groups indicates that while these EID regimens are associated with significantly lower PML risk than SID, the risk is not completely eliminated. No cases of PML were observed with the more stringent tertiary analysis, although the EID- $3^{\circ}$ group was relatively small $(n=815)$. Most of the cases of EID PML described here had multiple risk factors for PML, including longer overall natalizumab treatment duration, longer periods of SID before switching to EID, and a greater likelihood of prior immunosuppressant use than patients in the corresponding overall EID cohorts. In addition, several of the cases of EID PML had returned to SID before PML diagnosis. In a previously published case report of PML in a patient receiving natalizumab EID, the affected patient also had elevated PML risk factors, including a prolonged period of SID preceding EID and an anti-JCV antibody index $>1.5 .^{13}$

The biological mechanisms underlying the observed PML risk reduction require additional research, but partial reversal of the pharmacodynamic effects of natalizumab, including decreased receptor saturation, increased soluble vascular cell adhesion molecule expression, and a reduced natalizumabinduced peripheral lymphocytosis, has been reported to occur 4 to 8 weeks after the last dose ${ }^{14}$ and may allow the reestablishment of some immune surveillance in the CNS. The pathogenesis of PML is complex, and natalizumab may increase PML risk via mechanisms other than or in addition to reducing immune surveillance. ${ }^{15}$ Therefore, alternative hypotheses for the observed risk reduction with EID that are not based on an increase in immune surveillance should also be considered. 
Table 3 PML HR (95\% CI) for EID vs SID in the sensitivity and post hoc selection bias analyses

\begin{tabular}{|c|c|c|c|c|}
\hline Planned analysis & $\begin{array}{l}\text { Sensitivity analysis: inclusion of } \\
\text { cases of PML without known } \\
\text { anti-JCV antibody-positive } \\
\text { status }^{\mathrm{a}}\end{array}$ & $\begin{array}{l}\text { Sensitivity } \\
\text { analysis: } \\
\text { alternative EID } \\
\text { inclusion criteriab }^{b}\end{array}$ & $\begin{array}{l}\text { Post hoc analysis: inclusion of } \\
\text { cases of PML without known } \\
\text { anti-JCV antibody-positive } \\
\text { status and patients with dosing } \\
\text { gaps }^{c}\end{array}$ & $\begin{array}{l}\text { Post hoc analysis: } \\
\text { duration of anti-JCV } \\
\text { antibody-positive } \\
\text { status }^{\mathrm{d}}\end{array}$ \\
\hline \multicolumn{5}{|c|}{$\begin{array}{l}\text { Primary analysis: EID in } \\
\text { the last } 18 \text { mo of } \\
\text { treatment }\end{array}$} \\
\hline \multicolumn{5}{|l|}{$\begin{array}{l}\leq 15 \text { Infusions in the } \\
\text { last } 18 \mathrm{mo}\end{array}$} \\
\hline EID-1 ${ }^{\circ}, n$ & 1,989 & 998 & 7,029 & 1,988 \\
\hline SID-1 ${ }^{\circ}, n$ & 13,199 & 14,122 & 17,185 & 13,132 \\
\hline PML HR $(95 \% \mathrm{Cl})$ & $0.05(0.02-0.16)$ & $0.10(0.02-0.45)$ & $0.10(0.04-0.20)$ & $0.05(0.01-0.18)$ \\
\hline
\end{tabular}

Secondary analysis: EID

lasting $\geq 6$ mo at any

time in treatment

history

\begin{tabular}{lllll}
\hline $\begin{array}{l}\text { S10 Infusions over } \mathbf{1 2} \\
\mathbf{m o}\end{array}$ & \multicolumn{3}{l}{} & \\
\hline EID-2 ${ }^{\circ}, \mathbf{n}$ & 3,336 & 1,870 & 9,593 & 3,331 \\
\hline SID-2 ${ }^{\circ}, \mathbf{n}$ & 15,489 & 17,902 & 16,282 & 15,424 \\
\hline PML HR (95\% Cl) & $0.09(0.04-0.18)$ & $0.01(<0.01-0.09)$ & $0.16(0.10-0.24)$ & $0.11(0.04-0.26)$ \\
\hline
\end{tabular}

Tertiary analysis:

majority of treatment

received as EID

\begin{tabular}{lllll}
\hline $\begin{array}{l}\text { <10 Infusions per year } \\
\text { over the duration of } \\
\text { infusion history }\end{array}$ & & & & \\
\hline EID-3 $3^{\circ}, \mathbf{n}$ & 815 & NA & 6,307 & NA \\
\hline SID-3 $3^{\circ} \mathbf{n}$ & 23,239 & NA & 27,336 & NA \\
\hline PML HR (95\% CI) & $<0.01^{\mathrm{e}}$ & NA & $0.08(0.03-0.17)$ & NA \\
\hline
\end{tabular}

Abbreviations: $\mathrm{Cl}=$ confidence interval; EID = extended interval dosing; $\mathrm{HR}=$ hazard ratio; JCV = JC virus; $\mathrm{NA}=$ not analyzed; $\mathrm{PML}=$ progressive multifocal leukoencephalopathy; SID = standard interval dosing.

Figure 1 provides definitions of EID and SID in the primary, secondary, and tertiary analyses.

${ }^{a}$ Cases of PML assumed to be anti-JCV antibody positive and occurring before 2012 were added to the analysis populations. This added 1 case of EID and 67 cases of SID in the primary analysis, 5 cases of EID and 65 cases of SID in the secondary analysis, and 0 cases of EID and 71 cases of SID in the tertiary analysis.

${ }^{\mathrm{b}}$ Alternative EID definitions were $\leq 13$ infusions in the last 18 months in the primary analysis and $\leq 9$ infusions over 12 months in the secondary analysis. An alternative definition in the tertiary analysis was not explored.

' Patients with dosing gaps >12 weeks between infusions were added to the pre-2012 PML case sensitivity analysis cohorts.

${ }^{\mathrm{d}}$ Cox regression modeling of JCV status as a time-varying covariate, EID vs SID. This model was not tested in the tertiary analysis.

e The $95 \% \mathrm{CI}$ was not estimable because no cases of PML occurred in the EID-3 $3^{\circ}$ group.

The conclusions of this study are limited by several inherent biases. Patients on EID received more doses of natalizumab than patients on SID, which could have introduced a selection bias favoring more cases of PML in the EID cohorts because natalizumab exposure is a known PML risk factor. Conversely, most patients had received $>2$ years of SID treatment without developing PML before starting EID, so the EID groups may have included patients with inherently reduced risk of PML, thereby introducing a selection bias in favor of fewer cases of PML in the EID groups. In addition, anti-JCV antibody index data are not available for all patients in TOUCH; therefore, we do not know whether index values differ between the EID and SID cohorts and whether any such difference plays a role in the risk reductions observed in this study. Because EID is used as an offlabel strategy in clinical practice to reduce PML risk, antiJCV antibody index values might be higher in patients on EID than in those on SID, as was observed in a retrospective study of natalizumab EID. ${ }^{11}$ If this is true, the risk reductions seen in the EID cohorts described here could potentially be even larger in EID and SID patient populations with the same distributions of anti-JCV antibody index values. Lastly, we note that the Kaplan-Meier risk estimates are subject to increasing levels of uncertainty over time due to reductions in the cohort population sizes, especially beyond 5 years of treatment. However, the EID and SID 
Table 4 Life-table estimates of PML risk in patients included in the primary, secondary, and tertiary analyses

\begin{tabular}{|c|c|c|c|c|c|c|c|}
\hline \multirow[b]{3}{*}{$\begin{array}{l}\text { Natalizumab exposure } \\
\text { epoch }^{a}\end{array}$} & \multirow[b]{3}{*}{$\begin{array}{l}\text { No. of } \\
\text { infusions }\end{array}$} & \multicolumn{6}{|c|}{ Estimated risk of PML per 1,000 patients (No. of cases per adjusted no. of patients) } \\
\hline & & \multicolumn{2}{|c|}{ Primary analysis } & \multicolumn{2}{|c|}{ Secondary analysis } & \multicolumn{2}{|c|}{ Tertiary analysis } \\
\hline & & $\begin{array}{l}\text { EID-1ํ } \\
\text { group }\end{array}$ & SID-1ํำ group & EID-2 ${ }^{\circ}$ group & SID-2 ${ }^{\circ}$ group & $\begin{array}{l}\text { EID-3ㅇ } \\
\text { group }\end{array}$ & SID- $3^{\circ}$ group \\
\hline 1 & $1-12$ & $0(0 / 1,806)$ & $0(0 / 11,890)$ & $0(0 / 2,980)$ & $0(0 / 13,049)$ & $0(0 / 662)$ & $0(0 / 18,364)$ \\
\hline 2 & $13-24$ & $0(0 / 1,659)$ & $0.28(3 / 10,907)$ & $0(0 / 2,722)$ & $0.60(6 / 9,921)$ & $0(0 / 510)$ & $0.52(7 / 13,425)$ \\
\hline 3 & $25-36$ & $0(0 / 1,366)$ & $0.46(4 / 8,608)$ & $0.44(1 / 2,292)$ & $0.46(3 / 6,514)$ & $0(0 / 371)$ & $0.42(4 / 9,603)$ \\
\hline 4 & $37-48$ & $0(0 / 1,080)$ & $2.02(13 / 6,439)$ & $0(0 / 1,841)$ & $2.58(12 / 4,650)$ & $0(0 / 265)$ & $1.79(13 / 7,254)$ \\
\hline 5 & $49-60$ & $1.23(1 / 810)$ & $3.96(19 / 4,801)$ & $1.45(2 / 1,380)$ & $4.14(14 / 3,385)$ & $0(0 / 169)$ & $3.67(20 / 5,443)$ \\
\hline 6 & $61-72$ & $1.70(1 / 589)$ & $4.46(15 / 3,363)$ & $2.04(2 / 980)$ & $4.74(11 / 2,323)$ & $0(0 / 104)$ & $4.16(16 / 3,848)$ \\
\hline
\end{tabular}

Abbreviations: $\mathrm{EID}=$ extended interval dosing; PML = progressive multifocal leukoencephalopathy; SID = standard interval dosing.

PML risk is shown as the incidence rate per 1,000 patients (number of cases of PML per adjusted number of patients at risk) in anti-jC virus antibody-positive patients without prior immunosuppressant use for the primary and secondary definitions. Patients with prior immunosuppressant use could not be analyzed due to the insufficient number of patients. The adjusted number of patients at risk was 95 in the EID- $1^{\circ}$ group, 689 in the SID- $1^{\circ}$ group, 171 in the EID- $2^{\circ}$ group, and 747 in the SID- $2^{\circ}$ group. PML risk could not be calculated in the tertiary analysis of EID because no cases of PML occurred in this analysis. Figure 1 provides definitions of EID and SID under the primary, secondary, and tertiary analyses.

${ }^{\text {a }}$ Data beyond 6 years are not shown.

curves are well separated even at 60 months (5 years) of natalizumab treatment, when there are still substantial numbers of patients in all 3 analysis groups. The TOUCH program is ongoing, so future analyses of the TOUCH dataset will add more patients and observation time to each of the 3 groups and should provide greater certainty for the risk estimates.

Finally and most important, because the TOUCH program does not collect information about therapeutic efficacy, we could not assess the benefit-risk profile of EID compared with SID. Several studies of patient outcomes after natalizumab discontinuation indicate that MS disease activity is suppressed for at least 6 weeks and possibly as long as 12 weeks after the last administration. ${ }^{16-19}$ Furthermore, 2 retrospective studies have suggested that natalizumab efficacy is not compromised by EID regimens. ${ }^{10,11}$ However, the findings from these studies are limited by nonrandomized designs, small study populations, variable dosing practices, and potential selection biases in the EID study populations. In contrast to the clinical results, model-based simulations of natalizumab exposure have suggested that EID regimens (with 6- to 8-week intervals) may not confer adequate protection against MS disease activity. $^{20}$

The information provided in this study is highly relevant to health care providers and patients considering initiating or continuing natalizumab therapy. However, the benefit-risk profile of natalizumab EID has not been fully defined, and it is premature to suggest that SID should be replaced by EID or that the established PML risk stratification measures should be revised. ${ }^{9,21}$ An ongoing randomized prospective trial of EID vs SID (ClinicalTrials.gov identifier NCT03689972) will yield a more comprehensive understanding of both the effectiveness and safety of natalizumab EID.

\section{Author contributions}

Lana Zhovtis Ryerson: drafting/revising the manuscript, study concept or design, analysis or interpretation of data, accepts responsibility for conduct of research and will give final approval, study supervision. John Foley: drafting/revising the manuscript, study concept or design, analysis or interpretation of data, accepts responsibility for conduct of research and will give final approval. Ih Chang: study concept or design, analysis or interpretation of data, accepts responsibility for conduct of research and will give final approval, statistical analysis. Ilya Kister: drafting/revising the manuscript, study concept or design, analysis or interpretation of data, accepts responsibility for conduct of research and will give final approval. Gary Cutter: drafting/revising the manuscript, analysis or interpretation of data, accepts responsibility for conduct of research and will give final approval. Ryan R. Metzger: drafting/revising the manuscript, study concept or design, accepts responsibility for conduct of research and will give final approval. Judith $\mathrm{D}$. Goldberg: drafting/revising the manuscript, analysis or interpretation of data, accepts responsibility for conduct of research and will give final approval, statistical analysis. Xiaochun Li: drafting/revising the manuscript, accepts responsibility for conduct of research and will give final approval, statistical analysis. Evan Riddle: drafting/revising the manuscript, study concept or design, analysis or interpretation of data, accepts responsibility for conduct of research and will give final approval. Karen Smirnakis: data acquisition, analysis or interpretation of data, accepts responsibility for conduct of research and will give final approval. Rachna Kasliwal: drafting/ revising the manuscript, accepts responsibility for conduct of research and will give final approval, acquisition of data. Zheng Ren: analysis or interpretation of data, accepts responsibility for conduct of research and will give final approval, statistical analysis. Christophe Hotermans: drafting/revising the manuscript, study concept or design, analysis or interpretation of 
data, accepts responsibility for conduct of research and will give final approval. Pei-Ran Ho and Nolan Campbell: drafting/ revising the manuscript, study concept or design, analysis or interpretation of data, accepts responsibility for conduct of research and will give final approval, study supervision.

\section{Acknowledgment}

The authors acknowledge the many clinicians who pioneered the investigation of EID of natalizumab, including Joseph Herbert, MD, who was instrumental in organizing further study of this approach. All named authors meet the International Committee of Medical Journal Editors criteria for authorship for this manuscript and take responsibility for the integrity of the work as a whole. Biogen provided funding for medical writing support in the development of this manuscript; John Watson, $\mathrm{PhD}$, from Ashfield Healthcare Communications (Middletown, CT), with input from the authors, wrote the first draft and revised subsequent drafts of the manuscript, and Joshua Safran from Ashfield Healthcare Communications copyedited and styled the manuscript per journal requirements. Biogen reviewed and provided feedback on the manuscript to the authors.

\section{Study Funding}

Funded by Biogen.

\section{Disclosure}

L. Zhovtis Ryerson reports personal compensation for speaker bureau activities from Biogen, Genentech, and Teva and advisory board activities from Biogen and Celgene and research support from Biogen. J. Foley reports personal compensation and compensation for consulting activities from Biogen, Genentech, Genzyme, and Teva. I. Chang is an employee of and may hold stock/stock options in Biogen. I. Kister has served on advisory boards for Biogen and Genentech. G. Cutter has served on data and safety monitoring boards for AMO Pharmaceuticals, Apotek, Horizon Pharmaceuticals, Merck, Merck/Pfizer, Modigenetech/Prolor, Neurim, Opko Biologics, Reata, Receptos/Celgene, Sanofi, Teva, NHLBI (Protocol Review Committee), and the National Institute of Child Health and Human Development (Obstetric-Fetal Pharmacology Research Unit oversight committee); has received compensation for consulting or advisory board service from Argenix, Atara Biotherapeutics, Bioeq $\mathrm{GmBH}$, the Consortium of MS Centers (grant), Genentech, Genzyme, Innate Therapeutics, Klein-Buendel, MedDay, Medimmune, Novartis, Opexa Therapeutics, Roche, Savara, Somahlution, Teva, TG Therapeutics, and Transparency Life Sciences; and is president of Pythagoras, a private consulting company. R. Metzger's spouse is employed by Sanofi and holds stock in Biogen. J. Goldberg and $\mathrm{X}$. Li report no disclosures relevant to the manuscript. E. Riddle, K. Smirnakis, R. Kasliwal, Z. Ren, C. Hotermans, P.-R. Ho, and N. Campbell are employees of and may hold stock/ stock options in Biogen. Go to Neurology.org/ $\mathrm{N}$ for full disclosures.

\section{Publication history}

Received by Neurology October 25, 2018. Accepted in final form June 11, 2019.

\section{References}

1. Miller DH, Khan OA, Sheremata WA, et al. A controlled trial of natalizumab for relapsing multiple sclerosis. N Engl J Med 2003;348:15-23.

2. Polman $\mathrm{CH}, \mathrm{O}$ 'Connor PW, Havrdova E, et al. A randomized, placebo-controlled trial of natalizumab for relapsing multiple sclerosis. N Engl J Med 2006;354:899-910.

3. Prosperini L, Sacca F, Cordioli C, et al. Real-world effectiveness of natalizumab and fingolimod compared with self-injectable drugs in non-responders and in treatmentnaive patients with multiple sclerosis. J Neurol 2017;264:284-294.

4. Butzkueven H, Kappos L, Pellegrini F, et al. Efficacy and safety of natalizumab in multiple sclerosis: interim observational programme results. J Neurol Neurosurg Psychiatry 2014;85:1190-1197.

5. Rudick RA, Sandrock A. Natalizumab: a4-integrin antagonist selective adhesion molecule inhibitors for MS. Expert Rev Neurother 2004;4:571-580.

6. Stuve O, Bennett JL. Pharmacological properties, toxicology and scientific rationale for the use of natalizumab (Tysabri) in inflammatory diseases. CNS Drug Rev 2007; 13:79-95.

7. Tysabri (natalizumab) [prescribing information]. Cambridge: Biogen; 2018.

8. Bloomgren G, Richman S, Hotermans C, et al. Risk of natalizumab-associated progressive multifocal leukoencephalopathy. N Engl J Med 2012;366:1870-1880.

9. Ho PR, Koendgen H, Campbell N, Haddock B, Richman S, Chang I. Risk of natalizumab-associated progressive multifocal leukoencephalopathy in patients with multiple sclerosis: a retrospective analysis of data from four clinical studies. Lancet Neurol 2017; 16:925-933.

10. Bomprezzi R, Pawate S. Extended interval dosing of natalizumab: a two-center, 7-year experience. Ther Adv Neurol Disord 2014;7:227-231.

11. Zhovtis Ryerson L, Frohman TC, Foley J, et al. Extended interval dosing of natalizumab in multiple sclerosis. J Neurol Neurosurg Psychiatry 2016;87:885-889.

12. Risk Evaluation and Mitigation Strategy (REMS): TYSABRI Outreach: Unified Commitment to Health $\left(\mathrm{TOUCH}^{\odot}\right)$ prescribing program [online]. Available at: fda.gov/downloads/ Drugs/DrugSafety/PostmarketDrugSafetyInformationforPatientsandProviders/ UCM288126.pdf. Accessed May 19, 2018.

13. Hervás-García JV, Presas-Rodríguez S, Crespo-Cuevas AM, et al. Progressive multifocal leukoencephalopathy associated to natalizumab extended dosing regimen. Neurodegener Dis Manag 2015;5:399-402.

14. Plavina T, Muralidharan KK, Kuesters G, et al. Reversibility of the effects of natalizumab on peripheral immune cell dynamics in MS patients. Neurology 2017;89: $1584-1593$.

15. Major EO, Yousry TA, Clifford DB. Pathogenesis of progressive multifocal leukoencephalopathy and risks associated with treatments for multiple sclerosis: a decade of lessons learned. Lancet Neurol 2018;17:467-480.

16. Fox RJ, Cree BA, De Seze J, et al. MS disease activity in RESTORE: a randomized 24-week natalizumab treatment interruption study. Neurology 2014;82: $1491-1498$

17. Kappos L, Radue EW, Comi G, et al. Switching from natalizumab to fingolimod: a randomized, placebo-controlled study in RRMS. Neurology 2015;85:29-39.

18. Grimaldi LM, Prosperini L, Vitello G, Borriello G, Fubelli F, Pozzilli C. MRI-based analysis of the natalizumab therapeutic window in multiple sclerosis. Mult Scler 2012; 18:1337-1339.

19. Berkovich R, Togasaki DM, Cen SY, Steinman L. CD4 cell response to interval therapy with natalizumab. Ann Clin Transl Neurol 2015;2:570-574.

20. Muralidharan KK, Steiner D, Amarante D, et al. Exposure-disease response analysis of natalizumab in subjects with multiple sclerosis. J Pharmacokinet Pharmacodyn 2017; 44:263-275.

21. Physician information and management guidelines for multiple sclerosis patients on TYSABRI therapy [online]. Available at: hpra.ie/docs/default-source/3rd-partydocuments/tysabri-physician-information-and-management-guidelines-(version-1527th-april-2016).pdf?sfvrsn=2. Accessed January 8, 2019. 


\section{Neurology}

\section{Risk of natalizumab-associated PML in patients with MS is reduced with extended interval dosing \\ Lana Zhovtis Ryerson, John Foley, Ih Chang, et al.}

Neurology 2019;93;e1452-e1462 Published Online before print September 12, 2019

DOI 10.1212/WNL.0000000000008243

This information is current as of September 12, 2019

\section{Updated Information \& Services}

References

Citations

Subspecialty Collections

Permissions \& Licensing

Reprints including high resolution figures, can be found at: http://n.neurology.org/content/93/15/e1452.full

This article cites 18 articles, 5 of which you can access for free at: http://n.neurology.org/content/93/15/e1452.full\#ref-list-1

This article has been cited by 3 HighWire-hosted articles: http://n.neurology.org/content/93/15/e1452.full\#\#otherarticles

This article, along with others on similar topics, appears in the following collection(s):

\section{Class III}

http://n.neurology.org/cgi/collection/class_iii

Cohort studies

http://n.neurology.org/cgi/collection/cohort_studies

Harm/ risk (analysis)

http://n.neurology.org/cgi/collection/harm__risk_analysis

Incidence studies

http://n.neurology.org/cgi/collection/incidence_studies

Multiple sclerosis

http://n.neurology.org/cgi/collection/multiple_sclerosis

Information about reproducing this article in parts (figures,tables) or in its entirety can be found online at:

http://www.neurology.org/about/about_the_journal\#permissions

Information about ordering reprints can be found online:

http://n.neurology.org/subscribers/advertise

Neurology ${ }^{\circledR}$ is the official journal of the American Academy of Neurology. Published continuously since 1951, it is now a weekly with 48 issues per year. Copyright Copyright ( 2019 The Author(s). Published by Wolters Kluwer Health, Inc. on behalf of the American Academy of Neurology.. All rights reserved. Print ISSN: 0028-3878. Online ISSN: 1526-632X.

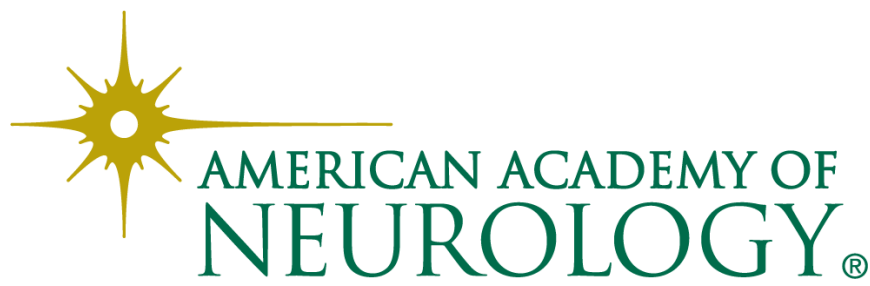

